\title{
Recommendation System for Analyzing the Preference Data of the Multimedia Software Tools in Education
}

\author{
Manal S. F. Alharbi ${ }^{1}$, El-Sayed M. El-kenawy ${ }^{2}$ \\ Computer department, The higher institute of telecommunication and navigation Public authority for applied education \\ and Training (PAAET), Kuwait ${ }^{1}$ \\ Department of Communications and Electronics, Delta Higher Institute of Engineering and Technology (DHIET), \\ Mansoura, 35111, Egypt $^{2}$
}

\begin{abstract}
In this article, we suggest an online course recommendation framework that aids and encourages learners in taking awareness tests and selecting the right curriculum for them. Multimedia is the discipline dealing with the computer-assisted integration of text, graphics, drawings, still and moving images (Video), animation, audio, and all other medium in which any Every kind of digital information may be interpreted, stored, distributed, and treated. Multimedia can be stored and played back, interpreted, worked with, or controlled by information retrieval systems such as high-tech and automated computers, but it can also be used in real time during a show. Digital media techniques for preserving and communicating with multimedia materials are known as multimedia devices. Multimedia stands out from the many media used in fine art; for example, when it includes audio, it has a wider scope. In the early days of multimedia, "rich media" meant collaborative multimedia, and "hypermedia" meant a multimedia technology.
\end{abstract}

Keywords: Recommendation System, Video, Graphics, Multimedia, Education.

\section{INTRODUCTION}

Referral implies count on transitivity; it is important to distinguish between leave and also the ability to suggest. Nonetheless, this functional rely on should be looked at to be indirect, given that U1 has actually not straight noted or even experienced U3's skill-sets[1-5]. Any efficiency has cultivated an unavoidable fragment of mixed media. It has sparked a wide range of debates, ranging from occupying to schooling and studying. As the Internet has increased in popularity, so has the market for mixed-media content. Multimedia is a category of media that combines a number of comfortable facts as well as information processing. to inform or entertain the user (e.g. material, sound, graphics, computer animation, and video capture interactivity)[6-12]. The term "mixed media" often refers to the use of mobile media in retail stores and the comprehension of digital media materials. Interactive technology is similar to traditional art forms, but it offers a broader range of possibilities. The words "wealthy media" and "interactive media" are synonymous. Multimedia[13-15].

A multimedia application is one that incorporates a variety of media channels, such as text, graphics, photographs, sound/audio, animation, and/or video. Hypermedia is one of the styles of multimedia applications.

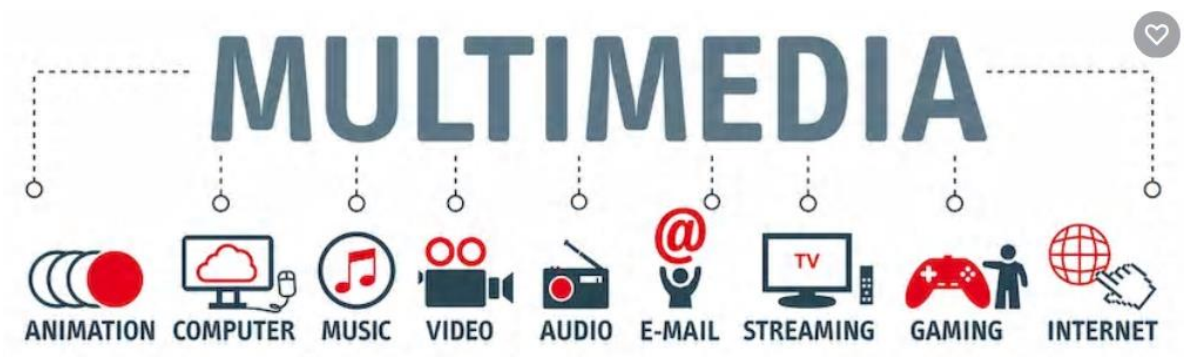

Figure 1 : Multimedia Elements/Components: 


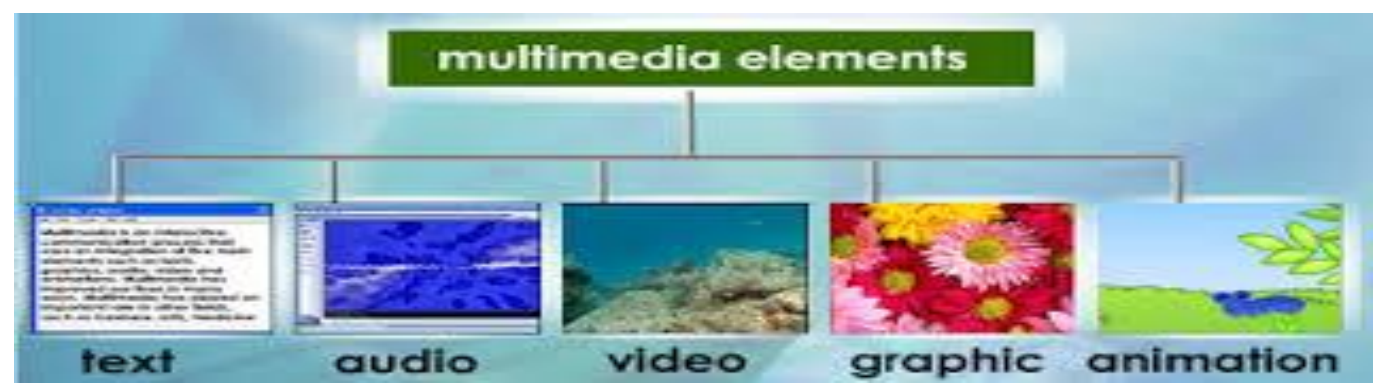

Types of media:

1. Traditional media (Such as Text, Image). Continuous media (Such as video, audio).

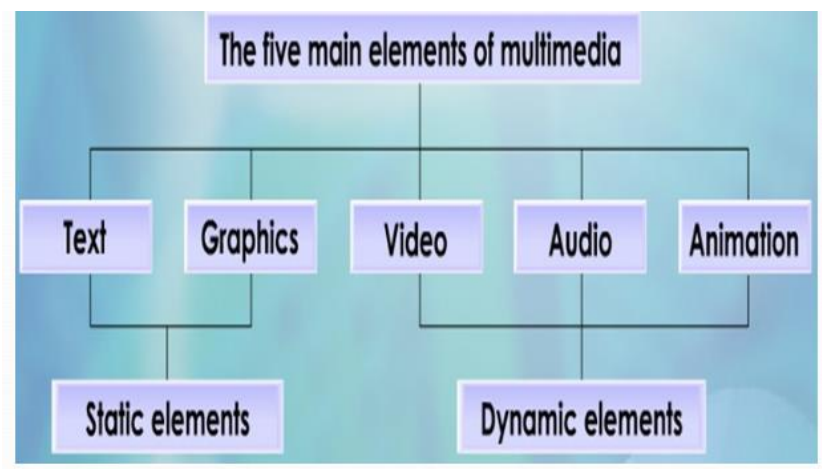

Figure 2 : Types of Media

\section{Static Graphics images:}

When you think about graphics pictures, you most often think of "still" images, such as photos used in a painting or diagram. In these types of images, there is no occurrence. Nonetheless, graphics pictures are an integral part of mixed media because humans are modality re-adjusted[16-20].

\section{Audio Sound:}

The integration of audio noise into an interactive media programme could provide the user with information that would not be accessible in any other type of announcement. Other forms of information cannot be effectively absorbed without the use of audio. Giving a precise word-based definition of the bear of a heart or even the Sound of the water, for example, is extremely difficult[21-25].

\section{Full-Motion Video}

A full-motion film, like the pictures on a tv, will potentially add a lot more to an immersive media programme. Despite the fact that full-motion streaming footage seems to be similar, which is an ideal way to integrate valuable knowledge into a mixed media treatment, it is nowhere near the high quality you might expect after viewing tv[26-30].

\section{Animation}

Changing graphics images are referred to as animation. The involvement of someone providing MOUTH-TOMOUTH RESUSCITATION makes learning internal body organ revitalization much simpler than analysing a stationary photo, just as a fixed graphics image is an all-powerful mode of human operation, so is computer animation[31-35].

\section{MULTIMEDIA TOOLS AND APPLICATIONS:}

A mixed media request is one that involves text, images, pictures, sound/audio, animation, and video recording, among other media. The multimedia meeting will cover specific tools for multimedia solutions as well as important mixedmedia applications. It includes sound, video capture, virtual reality and 3-D imaging, virtual reality and 3-D image resolution, multimedia, and virtual reality and 3-D image resolution and Artificial Intelligence. Interactive media solutions are exciting and creative multimedia devices that bind information that has been changed 
for the user in a non-linear fashion[36]. Computer programming, stability, individual computer user interfaces, and interactive media function establishments are among the normal and unfamiliar features of mixed media chronicle discussed at the multimedia meeting[37].The image below shows the most popular multimedia softwares and social media network:

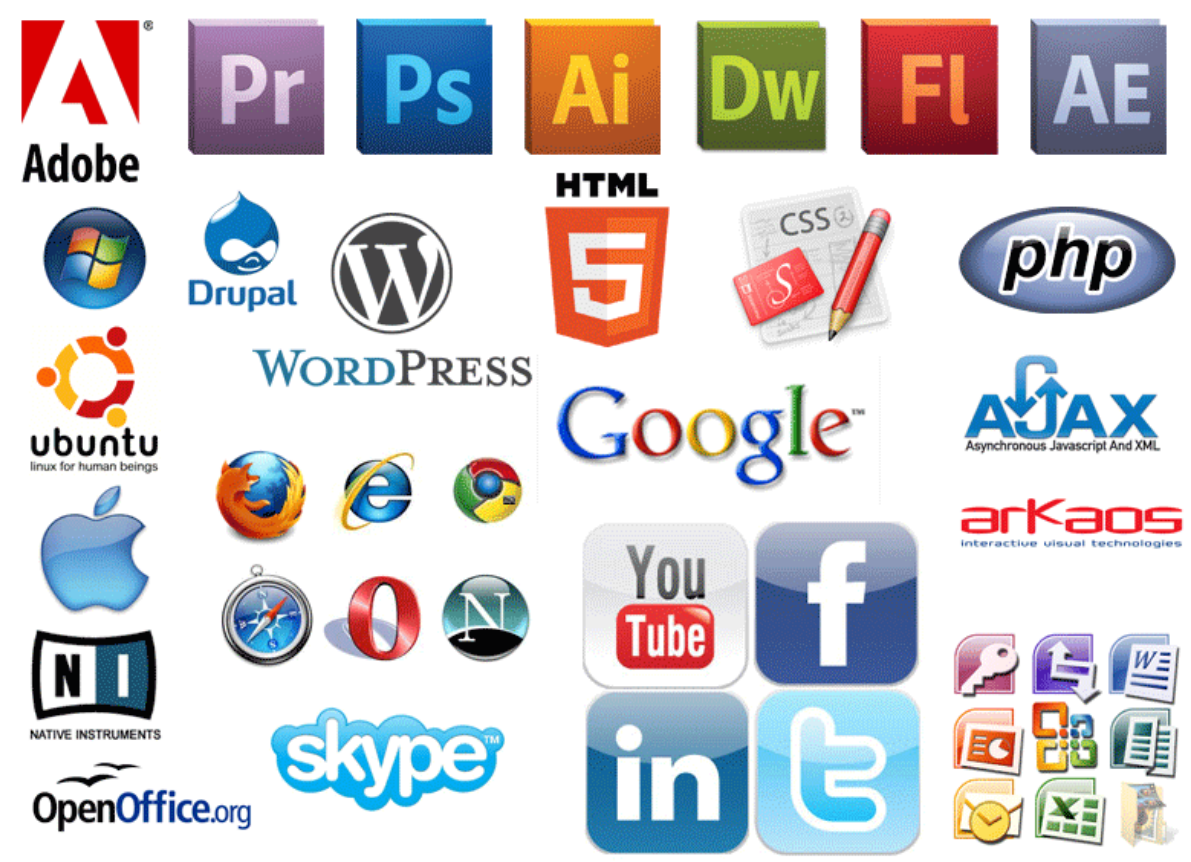

Figure 3 : Multimedia Tools and Applications

- Audio, video processing

- Education and Training

- Multimedia analysis and Internet

- Artificial Intelligence

- Virtual reality and 3-D -7Dimaging

- Wireless, Mobile Computing

- Animation and Graphics

- Visual Communication

- Pre-Production

- Films industrial

- Advertisement

- Communication of Information and Communication Media

- the Use of Geotechnology and Multimedia Resources in Cartography Lessons for Environmental Studies

- Multimedia Mapping on the Internet Using Commercial APIs

- Multicluster, mobile, multimedia radio network

- Multimedia technology on variables of knowledge, attitudes, and self-efficacy.

- Social media

- Multimedia software

\section{Multimedia in EdUCATion AND Training}

Multimedia in Education:

The condition multimedia was undoubtedly not in wide use until the late 1970s. Its exploitation due to the scientific mapping research performed did not start until the mid-1980s with the laser and CD-ROM development. The applying sciences have always adopted brand new technology to produce their products even more exact, more quickly made and generated in formats that were tuned to user desires and criteria. Multimedia was no exemption[38]. 


\section{International Journal of Advanced Research in Computer and Communication Engineering}

Vol. 10, Issue 3, March 2021

\section{DOI 10.17148/IJARCCE.2021.10330}

The planet on which our company reside is transforming quickly, and the industry of learning is experiencing these changes, especially as it relates to Media Solutions. The bygone days of a school having a separated audio-visual team are long gone! The growth in multimedia operation within the learning sector has sped up recently and appears established for continuous development later on. Teachers mainly require accessibility to finding outsources, which can easily sustain principle growth through students' assortment of means to meet individual learning requirements. The development of interactive media technologies for learning promotions brand new ways in which learning can occur in universities and the residence. Allowing teachers to have accessibility to interactive media learning sources, which assist practical idea development, enable the teacher to concentrate extra on being a facilitator of knowing while dealing with specific trainees. Expanding mixed media learning resources to the property represents an educational possibility and the prospective to boost student discovery. The elements used in multimedia possess all existed in the past. Interactive media blends these factors right into a highly effective brand new device, specifically in the palms of educators and trainees. Interactive multimedia weaves five primary forms of media into the understanding environment: text, video recording, audio, graphics and also animation. Considering that the mode of learning is interactive and not linear, a student or even instructor may select what to explore upcoming. For example, one performs not start on the 1st page of a straight record and review throughout. Hypermedia knowing to set is extra like designing a crawler's web, with one suggestion connected to another, allowing options in the student's road[39].

The multimedia innovations have possessed the best influence in education to enhance the current course of study, making it possible for both instant improvement and encouraging additional path of study growth. For example, the INFORMATION SUPERHIGHWAY acts as a storehouse of info that specific learners can hunt for subject matter web content that primarily fits their knowing plans. Multimedia applications for pcs have been established for single computing systems like the COMPUTER, Apple Mac computer and activities devices. Computer-based instruction courses (famously phoned CBTs) and also encyclopedia-like encyclopedia and almanacks. A CBT lets the consumer look at a collection of presentations, a text message about a particular subject, as well as affiliated depictions in several information styles. Edutainment is the combo of learning along with enjoyment, especially interactive media home entertainment. Interactive media were incorporating particular media in a one it has much more start of details. As a consequence, it is now commonly used in the areas of education and training. And with conventional methods, our professionals use audio visuals to present details instead of tables, designs, and other visual aids.Nowadays, the classroom demand is actually not restricted to that accepted approach; insteadIt necessitates the use of audio and visual media. Any of them is combined in one unit by digital media. The COMPUTER had a highresolution touch screen for use as an educational tool for digital media. All of which has resulted in the advancement of a wide range of computer-based teaching. The app pc helped path is open, and it is a valuable method for active learning.

\section{Multimedia in Training:}

There are several units and intelligent teaching programmes available to instruct students in a wide range of subjects, ranging from the arithmetic of an initial abrupt to a difficult surgical procedure for a healthcare trainee. Is there a sufficient number of audio samples in these tutorials? All positioning and repetition reveal an activity; as a resultObviously, it is concerned with sensible skills, and it provides many with that. These programmes work in a similar way to expert systems. They are often well equipped with decision-making utility-grade to control teaching after assessing a trainee's field experience. These guides combine a sufficient number of videos to clear up the trends.

\section{Recommendation System}

The best command recommendation formula based upon the correlation between consumers, their rating profile page, and highly recommend products strongly rated through comparable users is displayed in amount [40]. exactly how the formula operates supposes that if user U1 and also U2 price x things similarly or have identical behaviour, they will definitely rate or act upon other things similarly

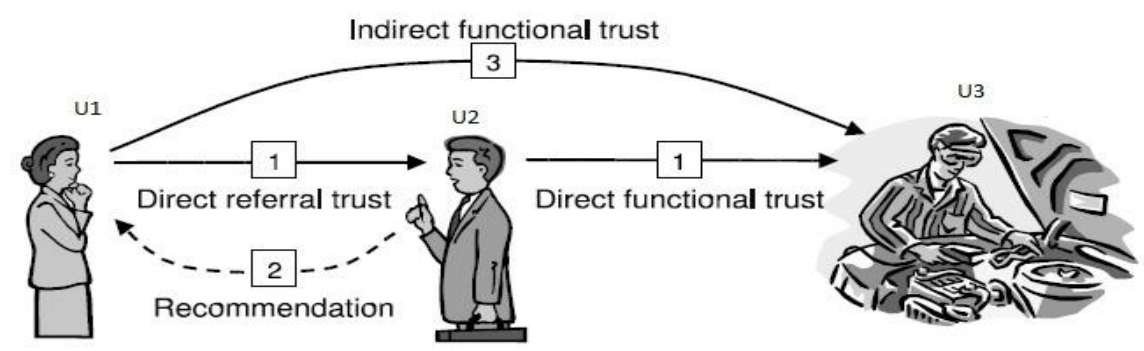




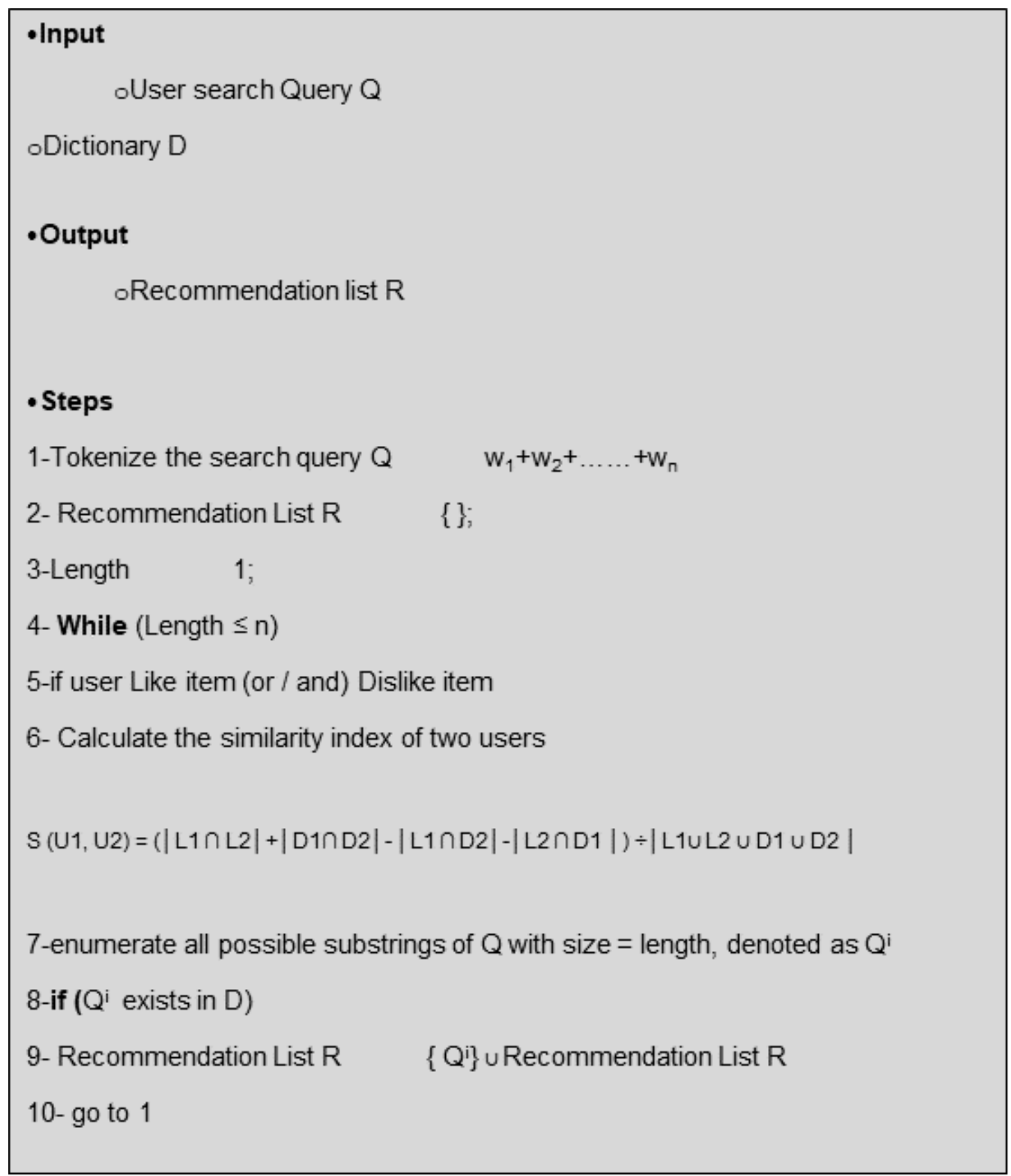

Figure 4 :Recommendation System Algorithm

\section{Survey}

Random participants were contacted by distributing the survey at the pupil café. The researchers were accessible to respond to inquiries. The participants turned in their finished studies to the researchers that right away coded the solution sheet so privacy may be preserved when analyzing the study actions. The questionnaire concerns were made; thus, simple yes and no answers were required. The survey was created in this way so that even more people will be willing to participate. 
International Journal of Advanced Research in Computer and Communication Engineering

Vol. 10, Issue 3, March 2021

DOI 10.17148/IJARCCE.2021.10330

\author{
Students \\ Ease of use \\ Cost/your time \\ Teaching/educational factors \\ Interaction \\ Organizational issues \\ Networking \\ Security and privacy
}

\title{
Ten questions:
}

- If your students are to be taught at least partly off-campus, to which technologies are they likely to have convenient and regular access at home or work?

- What digital skills do you expect your students to have before they start the program?

- What are the likely demographics of the students you will be teaching?

- How reliable is the technology?

- What really must be done face-to-face on this course?

- How important is it to enable learners to network beyond a course?

- What student information are you obliged to keep private and secure?

- What is the risk that by using a particular technology?

- What areas of teaching and learning?

- Do you trust the Training that you find online?

The aim of the questions was to learn more about the respondents, their educational experiences, and their behaviour. If the respondents on Education are present on the web portal, the answers show whether or not they are accessible. When the scores are visible on the website, it is presumed that they would represent this. Since the system's benefits allow for a way to test it, a user-centered assessment (UCE) is used for the cost savings,time savings, functioning of the system, reduce need for repairs, and increase user satisfaction.

Table 1: The Number of Arbitrary Study Participants

\begin{tabular}{|l|l|}
\hline Number of respondents & 85 \\
\hline Male & 51 \\
\hline Female & 34 \\
\hline Age & 19 to 22 years \\
\hline Undergraduate & \\
\hline Bachelor's degree & 68 \\
\hline Graduate studies & 12 \\
\hline
\end{tabular}

The number of arbitrary study participants totalled up to 85 individuals coming from the ages 19 to 22 years. Many of the pupils were undergraduates ( 80 per cent of the undergraduates). Merely 15 of the respondents had never used an online auction, which totalled up to about 17 per cent of the participants. Many of the staying participants had bought a product the previous month (about thirty-three per cent). 
DOI 10.17148/IJARCCE.2021.10330

Table 2 : Study Participants Analysis

\begin{tabular}{|l|l|l|}
\hline Independent Variable & \multicolumn{3}{l|}{} \\
\hline Scale Items : & $\mathbf{A}$ & $\mathbf{B}$ \\
\hline Factors & & \\
\hline Question 1 & $\mathbf{0 . 8 2 2}$ & $\mathbf{0 . 8 2 6}$ \\
\hline Question 2 & $\mathbf{0 . 6 2 5}$ & $\mathbf{0 . 7 2 1}$ \\
\hline Question 3 & $\mathbf{0 . 5 0 7}$ & $\mathbf{0 . 7 2 9}$ \\
\hline Question 4 & $\mathbf{0 . 5 3 3}$ & $\mathbf{0 . 6 7 2}$ \\
\hline Question 5 & $\mathbf{0 . 5 6 7}$ & $\mathbf{0 . 7 1 4}$ \\
\hline Question 6 & $\mathbf{0 . 8 8 9}$ & $\mathbf{0 . 8 8 9}$ \\
\hline Question 7 & $\mathbf{0 . 8 1 3}$ & $\mathbf{0 . 6 8 7}$ \\
\hline Question 8 & $\mathbf{0 . 6 0 1}$ & $\mathbf{0 . 7 8 3}$ \\
\hline Question 9 & $\mathbf{0 . 9 1 1}$ & $\mathbf{0 . 8 1}$ \\
\hline Question 10 & $\mathbf{0 . 8 9 9}$ & $\mathbf{0 . 9 2 1}$ \\
\hline $\begin{array}{l}\text { A - Positive Feeling Towards Multimedia in Education } \\
\text { B -Positive Feeling Towards Multimedia in Training }\end{array}$ \\
\hline
\end{tabular}
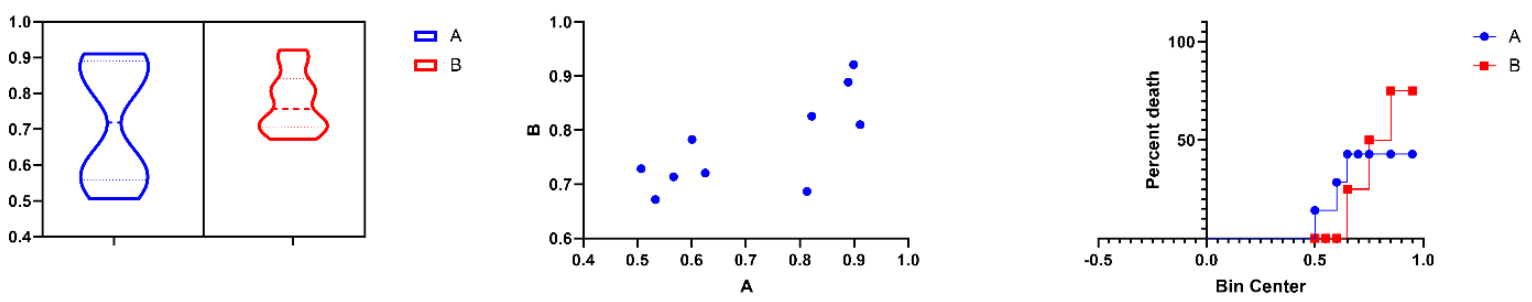

Table 3 :Descriptive statistics

\begin{tabular}{|l|r|r|}
\hline Minimum & 0.5070 & 0.6720 \\
\hline 25\% Percentile & 0.5585 & 0.7073 \\
\hline Median & 0.7190 & 0.7560 \\
\hline $75 \%$ Percentile & 0.8915 & 0.8418 \\
\hline Maximum & 0.9110 & 0.9210 \\
\hline Range & 0.4040 & 0.2490 \\
\hline Mean & 0.7167 & 0.7752 \\
\hline Std. Deviation & 0.1643 & 0.08518 \\
\hline Std. Error of Mean & 0.05196 & 0.02694 \\
\hline Sum & 7.167 & 7.752 \\
\hline
\end{tabular}

The results are received in the following table. The reason is made use of to assess the dependability of the variables. The Cronbach's $\alpha$ reflects the credibility between the things. When the value of a Cronbach's $\alpha$ is $\geq 0.7$, the construction products' internal congruity is excellent. The target is to figure out a Cronbach's $\alpha$ is $\geq 0.7$ but not equal to 0.95 or even more significant. That is actually because when Cronbach's $\alpha$ amounts to 0.95 or even higher, construct questions need to have to become extra distinct from one another. 


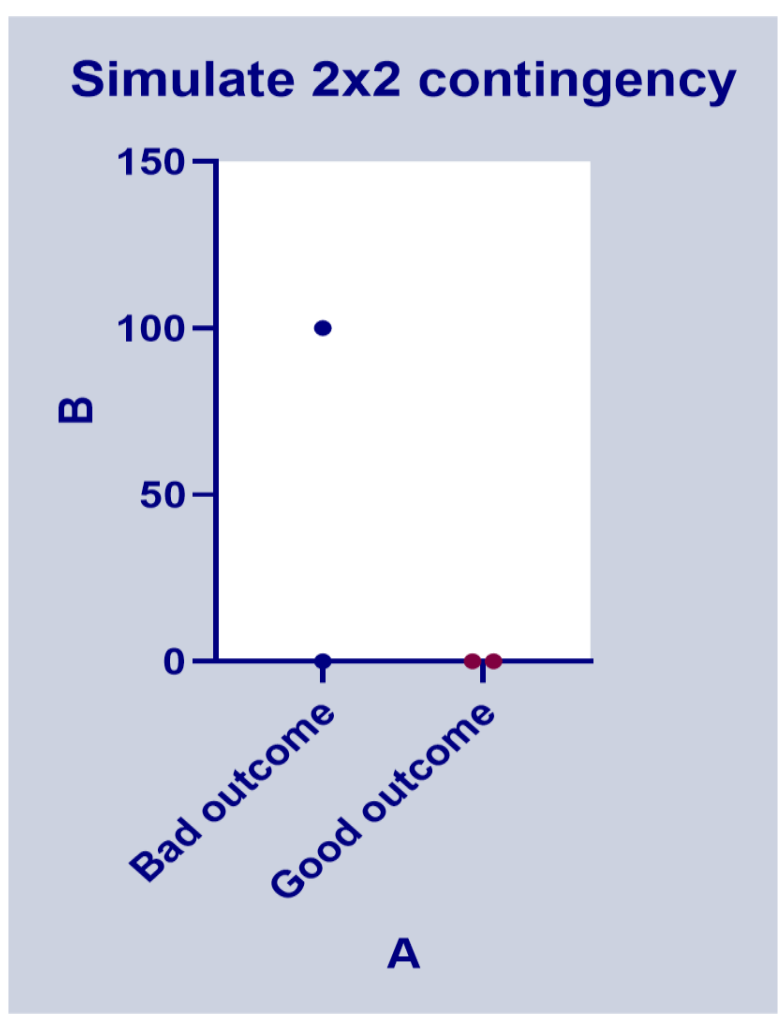

Figure 5 :Simulate Contingency

\section{IV.CONCLUSION}

This article offered a personalized recommendation system combining learner profiling, knowledge assessment, and trace analysis techniques to improve the learning process by recommending. We should learn about multimedia in two different ways. The first step is to consider multimedia in terms of meanings, histories, scenarios, and theoretical issues. The second strategy is to use digital to encourage debate and communication of ideas. Multimedia computer domain analysis is a form of "thinking-about" that is typically communicated through academic outlets including textbooks, journals, and lectures. "Thinking-with" is a digital career with its linguistic unit, hierarchical systems, resources, and outcomes. To think-with-multimedia means to use it to study and express ideas. It is crucial to think about multimedia, where what we think about is so new. Scholars in multimedia should take the challenge of developing multimedia to think about multimedia seriously and aspire to develop outstanding multimedia works in the humanities' cognitive material.

\section{REFERENCES}

[1] Mayer, R. E. (2002). Multimedia learning. In Psychology of learning and motivation (Vol. 41, pp. 85-139). Academic Press.

[2] Djamas, Djusmaini, and Vonny Tinedi. "Development of interactive multimedia learning materials for improving critical thinking skills." In Research Anthology on Developing Critical Thinking Skills in Students, pp. 507-525. IGI Global, 2021.

[3] Dawson, Kara, Jiawen Zhu, Albert D. Ritzhaupt, Pavlo Antonenko, Kendra Saunders, Jiahui Wang, and Linda Lombardino. "The influence of the multimedia and modality principles on the learning outcomes, satisfaction, and mental effort of college students with and without dyslexia." Annals of Dyslexia (2021): 1-23.

[4] Ye, Li, Hanjun Su, Jing Zhao, and Yongxin Hang. "The Impact of Multimedia Effect on Art Learning: Eye Movement Evidence from Traditional Chinese Pattern Learning." International Journal of Art \& Design Education (2021).

[5] Heo, Misook, and Natalie Toomey. "Learning with multimedia: The effects of gender, type of multimedia learning resources, and spatial ability." Computers \& Education 146 (2020): 103747.

[6] Heo, Misook, and Natalie Toomey. "Learning with multimedia: The effects of gender, type of multimedia learning resources, and spatial ability." Computers \& Education 146 (2020): 103747.

[7] S. Mirjalili, S. M. Mirjalili, and A. Lewis, "Grey wolf optimizer," Advances in Engineering Software, vol. 69, no. 0, pp. 46 - 61, 2014.

[8] Ibrahim, Abdelhameed, and El-Sayed M. El-kenawy. "Image Segmentation Methods Based on Superpixel Techniques: A Survey." Journal of Computer Science and Information Systems 15, no. 3 (2020).

[9] Ibrahim, Abdelhameed, and El-Sayed M. El-kenawy. "Applications and Datasets for Superpixel Techniques: A Survey." Journal of Computer Science and Information Systems 15, no. 3 (2020).

[10] Eid, Marwa M., El-Sayed M. El-kenawy, and Abdelhameed Ibrahim. "An Advanced Patient Health Monitoring System." Journal of Computer Science and Information Systems 17, no. 11 (2021).

[11] El-kenawy, El-Sayed M., Marwa M. Eid, and Abdelhameed Ibrahim. "Anemia Estimation for COVID-19 Patients Using A Machine Learning Model." Journal of Computer Science and Information Systems 17, no. 11 (2021). 


\title{
International Journal of Advanced Research in Computer and Communication Engineering
}

\author{
Vol. 10, Issue 3, March 2021
}

\section{DOI 10.17148/IJARCCE.2021.10330}

[12] El-kenawy, El-Sayed M., Marwa M. Eid, and Abdelhameed Ibrahim. "Automatic Identification from Noisy Microscopic Images." Journal of Computer Science and Information Systems 17, no. 11 (2021).

[13] M. M. Fouad, A. I. El-Desouky, R. Al-Hajj and E. M. El-Kenawy, "Dynamic Group-based Cooperative Optimization Algorithm," in IEEE Access, doi: 10.1109/ACCESS.2020.3015892.

[14] El-Kenawy, E. S. M. T., El-Desoky, A. I., \& Sarhan, A. M. (2014). A bidder strategy system for online auctions trust measurement. International Journal of Strategic Information Technology and Applications (IJSITA), 5(3), 37-47.

[15] Hassib, E. M., El-Desouky, A. I., Labib, L. M., \& El-kenawy, E. S. M. (2019). WOA+ BRNN: An imbalanced big data classification framework using Whale optimization and deep neural network. Soft Computing, 1-20.

[16] El-kenawy, E. S. M., El-Desoky, A. I., \& Al-rahamawy, M. F. (2012). Distributing Graphic Rendering using Grid Computing with Load Balancing. International Journal of Computer Applications, 975, 888

[17] El-kenawy, E. S. M. T. (2019). A Machine Learning Model for Hemoglobin Estimation and Anemia Classification. International Journal of Computer Science and Information Security (IJCSIS), 17(2).

[18] Hassib, E. M., El-Desouky, A. I., El-kenawy, E. S. M., \& Elghamrawy, S. (2019). An Imbalanced Big Data Mining Framework for Improving Optimization Algorithms Performance. IEEE Access.

[19] H. Hassan, A. I. El-Desouky, A. Ibrahim, E. M. El-kenawy and R. Arnous, (2020) "Enhanced QoS-based Model for Trust Assessment in Cloud Computing Environment," in IEEE Access. doi: 10.1109/ACCESS.2020.2978452

[20] El-Knawy, E. S. M. T., \& El-Desoky, A. I. (2016). TRUST MEASUREMENT FOR ONLINE AUCTIONS: PROPOSAL OF NEW MODEL. INTERNATIONAL JOURNAL OF INNOVATIVE COMPUTING INFORMATION AND CONTROL, 12(2), 385-394.

[21] El-sayed, M., El-Desoky, A. I., \& Sarhan, A. M. (2014). A bidder behavior learning intelligent system for trust measurement. International Journal of Computer Applications, 89(8).

[22] Arnous, R., \& El-Sayed Towfek, M. (2019). El-kenawy and M Saber. A Proposed Routing Protocol for Mobile Ad Hoc Networks. International Journal of Computer Applications, 178(41), 26-30.

[23] El-Sayed Towfek M El-kenawy. Trust Model for Dependable File Exchange in Cloud Computing. International Journal of Computer Applications 180(49):22-27, June 2018.

[24] El-Sayed Towfek M El-kenawy, M Saber and Reham Arnous. An Integrated Framework to Ensure Information Security Over the Internet. International Journal of Computer Applications 178(29):13-15, July 2019

[25] El-kenawy, E. S. M. T. (2018). Solar Radiation Machine Learning Production Depend on Training Neural Networks with Ant Colony Optimization Algorithms. IJARCCE, 7(5). doi: DOI10.17148/IJARCCE.2018.751

[26] E. M. El-Kenawy, M. M. Eid, M. Saber and A. Ibrahim, "MbGWO-SFS: Modified Binary Grey Wolf Optimizer Based on Stochastic Fractal Search for Feature Selection," in IEEE Access, vol. 8, pp. 107635-107649, 2020, doi: 10.1109/ACCESS.2020.3001151.

[27] E.-S. El-Kenawy and M. Eid, "Hybrid gray wolf and particle swarm optimization for feature selection," INTERNATIONAL JOURNAL OF INNOVATIVE COMPUTING INFORMATION AND CONTROL, vol. 16, no. 3, pp. 831-844, 2020.

[28] E. M. El-Kenawy and M. Saber, "Design and implementation of accurate frequency estimator depend on deep learning" International Journa 1 of Engineering \&Technology (IJET), vol. 9 , Issue 2, PP. 367-377, 2020 , DOI: 10.14419/ijet.v9i2.30473

[29] El-kenawy, E. S. T., El-Desoky, A. I., \& Al-rahamawy, M. F. (2012). Extended max-min scheduling using petri net and load balancing. Int. J. Soft Comput. Eng.(IJSCE), 2(4), 198-203.

[30] Hussien, Hussien Rezk, and M. El-Sayed. "El-Kenawy, and Ali I. El-Desouky." EEG Channel Selection Using A Modified Grey Wolf Optimizer."." European Journal of Electrical Engineering and Computer Science 5: 17-24.

[31] Ibrahim, Abdelhameed, and A. Tharwat. "Biometric authentication methods based on ear and finger knuckle images." International Journal of Computer Science Issues (IJCSI) 11, no. 3 (2014): 134.

[32] Ibrahim, Abdelhameed, Tarek Gaber, Takahiko Horiuchi, Vaclav Snasel, and Aboul Ella Hassanien. "Human thermal face extraction based on superpixel technique." In The 1st International Conference on Advanced Intelligent System and Informatics (AISI2015), November 28-30, 2015, Beni Suef, Egypt, pp. 163-172. Springer, Cham, 2016.

[33] Ibrahim, Abdelhameed, Mostafa Noshy, Hesham Arafat Ali, and Mahmoud Badawy. "PAPSO: A power-aware VM placement technique based on particle swarm optimization." IEEE Access 8 (2020): 81747-81764.

[34] Ibrahim, Abdelhameed, Takahiko Horiuchi, and Shoji Tominaga. "Illumination-invariant representation for natural color images and its application." In 2012 IEEE Southwest Symposium on Image Analysis and Interpretation, pp. 157-160. IEEE, 2012.

[35] Saber, Mohamed, and Marwa M. Eid. "Low power pseudo-random number generator based on lemniscate chaotic map." International Journal of Electrical \& Computer Engineering (2088-8708) 11, no. 1 (2021).

[36] Ibrahim, Abdelhameed, Hesham Arafat Ali, Marwa M. Eid, and El-Sayed M. El-kenawy. "Chaotic Harris Hawks Optimization for Unconstrained Function Optimization." In 2020 16th International Computer Engineering Conference (ICENCO), pp. 153-158. IEEE, 2020.

[37] El-kenawy, El-Sayed M., Seyedali Mirjalili, Abdelhameed Ibrahim, Mohammed Alrahmawy, M. El-Said, Rokaia M. Zaki, and Marwa M. Eid. "Advanced Meta-heuristics, Convolutional Neural Networks, and Feature Selectors for Efficient COVID-19 X-ray Chest Image Classification." IEEE Access (2021).

[38] Moudani, Walid, Grace Zaarour, El-Sayed M. Towfek El-Kenawy, Ali Ibraheem El-Desoky, Amany M. Sarhan, Mona FM Mursi, and Hossam Eldin H. Ahmed. "International Journal of Strategic Information Technology and Applications."

[39] Eid, Marwa M., El-Sayed M. El-kenawy, and Abdelhameed Ibrahim. "A Fast Real-Time Video Encryption/Decryption Technique Based on Hybrid Chaotic Maps." Journal of Computer Science and Information Systems 18, no. 9 (2021).

[40] Eid, Marwa M., El-Sayed M. El-kenawy, and Abdelhameed Ibrahim. "A New Hybrid Video Encryption Technique Based on Chaos Cryptography." 